\title{
A facile approach for the synthesis of 3,4-dihydropyrimidin-2-(1 H )-ones using a microwave promoted Biginelli protocol in ionic liquid
}

\author{
ABHISHEK N DADHANIA*, VAIBHAV K PATEL and DIPAK K RAVAL \\ Department of Chemistry, Sardar Patel University, Vallabh Vidyanagar 388 120, India \\ e-mail: abhishekdadhania@gmail.com
}

MS received 5 December 2011; revised 25 February 2012; accepted 6 March 2012

\begin{abstract}
Carboxy functionalized ionic liquid $\left[\mathrm{cmmim}^{-}\right]\left[\mathrm{BF}_{4}\right]$ has been demonstrated to be an efficient and green catalyst for the one pot synthesis of 3,4-dihydropyrimidin-2-(1H)-ones heterocycles under microwave irradiation. The ionic liquid-microwave strategy represents an easy access to Biginelli compounds with high yields and purity. The protocol was found to be compatible with different structurally diverse aldehydes. The ionic liquid was recycled and reused in at least six subsequent reactions with consistent activity.
\end{abstract}

Keywords. Ionic liquid; Biginelli reaction; microwave irradiation; recyclability.

\section{Introduction}

Research interest in 3,4-dihydropyrimidin-2-( $1 H$ )-ones ('Biginelli compounds', DHPMs), has surged rapidly, owing to the pharmacological properties ${ }^{1-5}$ associated with many derivatives of this privileged heterocyclic core. The biological activity ${ }^{1}$ of these Biginelli compounds has been found in the form of antiviral, antitumor, antibacterial and antiinflammatory properties. In addition to the medicinal applications, many functionalized DHPMs have emerged as potent calcium channel blockers, ${ }^{2}$ antihypertensive agents, ${ }^{3} \alpha_{1 \mathrm{a}}$ adrenergic antagonists ${ }^{4}$ and neuropeptide Y (NPY) antagonists. ${ }^{5}$ Several recently isolated marine alkaloids ${ }^{6}$ with interesting biological activities also contain the dihydropyrimidinone-5-carboxylate core. The best-known method for DHPMs is the classical Biginelli synthesis. ${ }^{7}$ Although it has been known for more than a century, it is still the most useful method for the preparation of such a class of compounds. Since 1893, the synthesis of the DHPMs nucleus by the Biginelli reaction procedure has been extensively explored. ${ }^{8}$ Many catalysts ${ }^{9}$ have been reported for the synthesis of DHPMs, either by modification in classical Biginelli reaction or by development of novel multistep strategies. In addition, many catalysts such as amberlyst$15 / \mathrm{AcOH},{ }^{10} \mathrm{HClO}_{4},{ }^{11} \mathrm{H}_{3} \mathrm{PW}_{12} \mathrm{O}_{40},{ }^{12} \mathrm{TMSCl} / \mathrm{MeCN},{ }^{13}$ PSSA $/ \mathrm{H}_{2} \mathrm{O},{ }^{14} \mathrm{I}_{2} / \mathrm{Al}_{2} \mathrm{O}_{3},{ }^{15}$ sulphated $\mathrm{ZrO}_{2},{ }^{16} \mathrm{SbCl}_{3} /$ $\mathrm{Al}_{2} \mathrm{O}_{3},{ }^{17}$ TsOH/AcOH, ${ }^{18}$ NBS/EtOH, ${ }^{19} \quad$ In $(\mathrm{OTf})_{3}{ }^{20}$

*For correspondence and $\mathrm{ZnI}_{2}{ }^{21}$ were employed for reaction along with microwave irradiation (scheme 1). However, limitations such as use of toxic solvents, expensive catalyst, requirement of excess reagents/catalysts, laborious work up procedures, etc. restrict the practical synthetic utility of this chemistry.

The concept of speeding up synthetic transformations by microwave irradiation has been the focus of considerable attention in recent years and is becoming an increasingly popular technology. ${ }^{22}$ Recently, popular trend in this area is to use ionic liquids or mixture of ionic liquids as reaction media in microwave animated transformation. ${ }^{23}$ Likewise, the use of roomtemperature ionic liquids (ILs) as green reaction media in organic transformation has gained considerable importance due to their solvating ability, negligible vapour pressure and easy recyclability. ${ }^{24}$ Moreover, due to their high polarity and ionic nature, ionic liquids couple very effectively with microwaves through a dipolar polarization and ionic conduction mechanism $^{25}$ to push the reaction in forward direction very quickly.

The literature survey reveals that the potentiality of microwave/ionic liquid (MW/ILs) synergetic couple uniquely for the synthesis of Biginelli compounds has not been explored much. Therefore, it appeared to us that a MW/ILs strategy would be ideally suited for the synthesis of this privileged heterocycle. Proceeding in the same direction, we opted to evolve an efficient and eco-friendly process for the preparation of ionic liquid 1-carboxymethyl-3-methylimidazolium tetrafluoroborate $[\mathrm{cmmim}]\left[\mathrm{BF}_{4}\right]$ via microwave irradiation. 


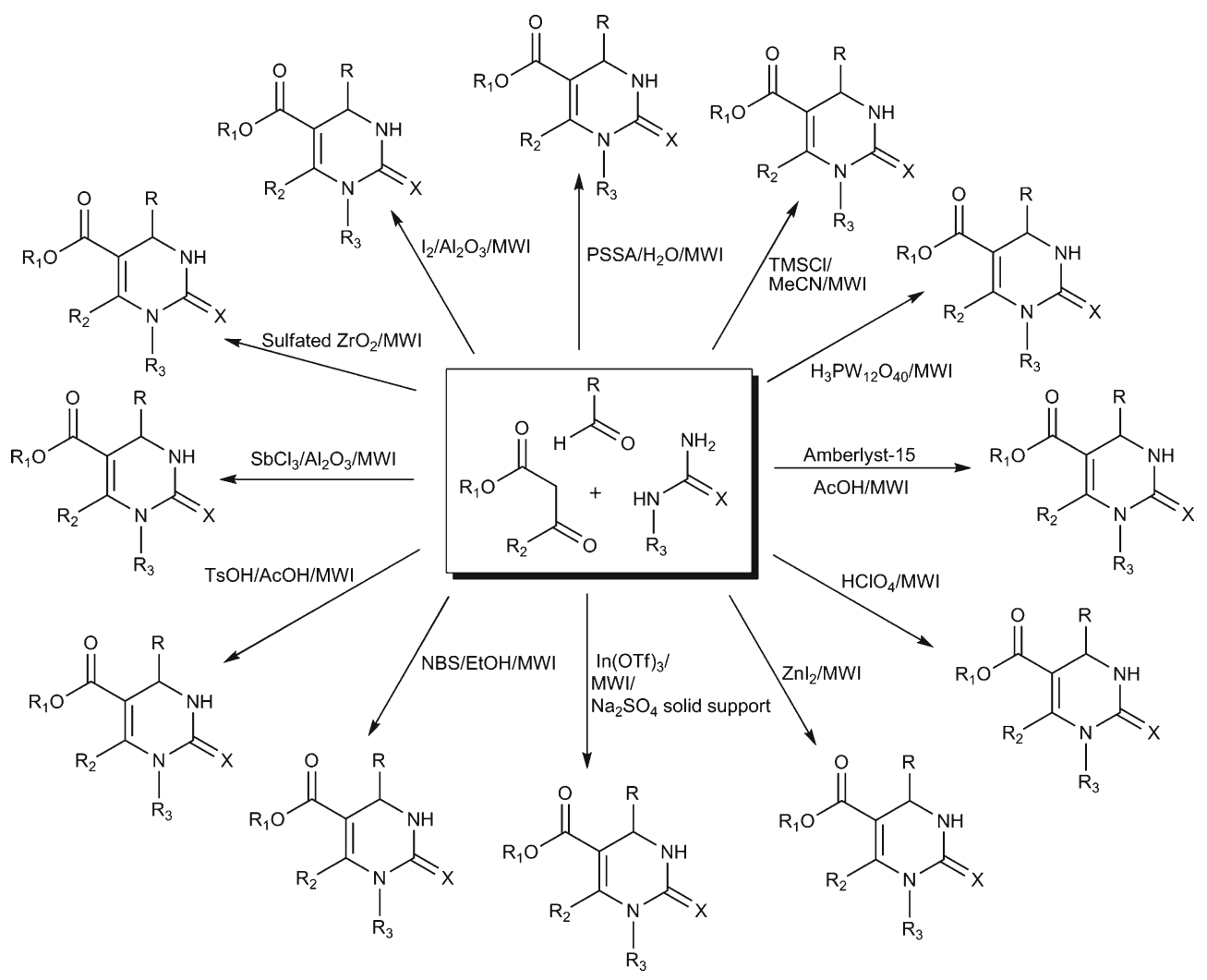

Scheme 1. Various catalysts employed for the synthesis of DHPMs under microwave irradiation.

We report here a microwave sponsored modified preparation of $[\mathrm{cmmim}]\left[\mathrm{BF}_{4}\right]$ and disclose the successful outcome of MW/ILs strategy to synthesize 3, 4-dihydropyrimidin-2-(1H)-ones heterocycle in excellent isolated yields. The IL could be recycled and successfully reused in at least six consequent runs. The process holds well without the need of additional catalyst.

\section{Experimental}

All chemicals were of research grade and were used as obtained from Sigma-Aldrich, Alfa-Aesar and SDFCL. The melting points were determined in capillary tubes using heavy paraffin liquid in Thiele tube. Melting points were uncorrected and were compared with the reported literature values. The reaction progress and purity of products were determined by TLC silica gel plates (Merck $60 \mathrm{~F}_{254}$ ). The reactions were performed in scientific microwave system (Catalyst system 'CATA-R', $700 \mathrm{~W}$ ) using $25 \mathrm{~mL}$ round-bottomed flask. IR Spectra were recorded on a Shimadzu FT-IR 8400 spectrometer. Mass spectra were recorded on AB APPLIED BIOSYSTEMS IMDS SCIEX, API-2000 LC/MS/MS instrument. ${ }^{1} \mathrm{H}$ NMR, ${ }^{13} \mathrm{C}$ NMR and DEPT-135 spectra were recorded on Bruker Avance $400 \mathrm{MHz}$ spectrometer in $\mathrm{CDCl}_{3} / \mathrm{DMSO}-\mathrm{d} 6$ with TMS as the internal standard.

\subsection{Synthesis of 1-carboxymethyl-3-methylimidazolium tetrafluoroborate [ $\mathrm{cmmim}^{2}\left[\mathrm{BF}_{4}\right]$ under microwave irradiation}

Synthesis of $[\mathrm{cmmim}]\left[\mathrm{BF}_{4}\right]$ was reported by Gonghua Song et al. via conventional method. ${ }^{26}$ We have successfully attempted the same under microwave irradiation in comparatively short duration. Aliquots of chloroacetic acid (1 equiv.) was added over a period of 60 min to 1-methyl-imidazole ( 1 equiv.) at room temperature under stirring, and then this set-up was irradiated in the MW oven 4 times at the 20\% power level $(140 \mathrm{~W})$ and 4 times at the $30 \%$ power level $(210 \mathrm{~W})$ for $60 \mathrm{~s}$ with $2 \mathrm{~min}$ intermittent cooling period after each irradiation cycle. The solid thus obtained was washed with acetonitrile, and dried under vacuum. The intermediate, 1-carboxymethyl-3-methylimidazolium chloride was obtained as a white solid (mp, $\left.172-174^{\circ} \mathrm{C}\right)$. The [cmmim][Cl] (1 equiv.) and $\mathrm{NaBF}_{4}$ (1 equiv.) were dissolved in $\mathrm{H}_{2} \mathrm{O}$ and irradiated in the $\mathrm{MW}$ oven at 
$60 \%$ power level $(420 \mathrm{~W})$ for $10 \mathrm{~min}$ with intermittent cooling of 2 min after 5 min of irradiation. Water was removed from the reaction mixture by subjecting it to distillation for $4 \mathrm{~h}$ at $80^{\circ} \mathrm{C}$ under reduced pressure $(10 \mathrm{mmHg})$ to give the product $[\mathrm{cmmim}]\left[\mathrm{BF}_{4}\right]$ as a slight yellowish oil. Ionic liquid was characterized by ${ }^{1} \mathrm{H}-\mathrm{NMR}$ and ${ }^{13} \mathrm{C}-\mathrm{NMR}$. All the data were in good agreement with the reported one.

\subsection{General procedure for the preparation of DHPMs}

A mixture of aldehyde $1(10 \mathrm{mmol})$, ethyl acetoacetate 2 (EAA, $10 \mathrm{mmol}$ ), urea (or thiourea) 3 (11 mmol) and $[\mathrm{cmmim}]\left[\mathrm{BF}_{4}\right](200 \mathrm{mg})$ was charged into a $25 \mathrm{~mL}$ round bottom flask. The mixture was stirred gently with a spatula for a few seconds and was subjected to microwave irradiation at $40 \%$ power level (CATA-R, $700 \mathrm{~W}$ ) for appropriate time as shown in table 1. After completion of the reaction (as indicated by TLC) the reaction mixture was poured onto crushed ice $(\sim 20 \mathrm{gm})$ and stirred well. The solid separated was washed with ice cold water and then recrystallized from hot ethanol or ethyl acetate to afford pure DHPMs, 4a-x. The combined aqueous filtrate was subjected to vacuum at $80^{\circ} \mathrm{C}$ under reduced pressure $(10 \mathrm{mmHg})$ for $4 \mathrm{~h}$ to leave behind the IL in near complete recovery, pure enough to recycle. The recovered ionic liquid was found to be equally effective for at least six cycles in the synthesis of $\mathbf{4 a}$.

\subsection{Spectral data of some selected compounds}

2.3a 5-Ethoxycarbonyl-6-methyl-4-phenyl-3,4dihydropyrimidin-2(1H)-one (4a): IR (KBr) 3233, 2954, 1730, 1690, 1206, $698 \mathrm{~cm}^{-1} ;{ }^{1} \mathrm{H}$ NMR $\delta 9.21(\mathrm{~s}$, $1 \mathrm{H}), 7.74(\mathrm{~s}, 1 \mathrm{H}), 7.25(\mathrm{~m}, 5 \mathrm{H}), 5.14(\mathrm{~s}, 1 \mathrm{H}), 3.98(\mathrm{q}$, $J=7.1 \mathrm{~Hz}, 2 \mathrm{H}), 2.25(\mathrm{~s}, 3 \mathrm{H}), 1.09(\mathrm{t}, J=7.1 \mathrm{~Hz}$, $3 \mathrm{H}) ;{ }^{13} \mathrm{C}$ NMR $\delta 13.9,17.7,53.9,59.1,99.2,126.1$, $127.1,128.3,144.7,148.2,152.0,165.2$. Calc. for

Table 1. Synthesis of DHPMs using various aldehydes with ethyl acetoacetate and urea/thiourea in $\left[\mathrm{cmmim}^{-}\left[\mathrm{BF}_{4}\right]\right.$.

\begin{tabular}{|c|c|c|c|c|c|c|c|}
\hline \multirow[b]{2}{*}{ Product } & \multirow[b]{2}{*}{$\mathrm{R}-$} & \multirow[b]{2}{*}{$X$} & \multicolumn{2}{|c|}{ Reaction time $(\min )^{\mathrm{a}}$} & \multicolumn{2}{|c|}{$\%$ Yield $^{\mathrm{b}}$} & \multirow[b]{2}{*}{$\mathrm{Mp} /{ }^{\circ} \mathrm{C}$ observed (lit.) } \\
\hline & & & $\mathrm{MW}$ & $\Delta$ & MW & $\Delta$ & \\
\hline $4 \mathbf{a}$ & $\mathrm{Ph}-$ & $\mathrm{O}$ & 1.5 & 90 & 97 & 92 & $201-202(202-204)^{28}$ \\
\hline $4 b$ & 4- $\mathrm{O}_{2} \mathrm{~N}-\mathrm{C}_{6} \mathrm{H}_{4}-$ & $\mathrm{O}$ & 3.0 & 240 & 96 & 88 & $206-208(207-209)^{29}$ \\
\hline $4 c$ & $4-\mathrm{F}-\mathrm{C}_{6} \mathrm{H}_{4}-$ & $\mathrm{O}$ & 2.5 & 180 & 93 & 83 & $174-176(175-176)^{31}$ \\
\hline $4 d$ & $3-\mathrm{Cl}-\mathrm{C}_{6} \mathrm{H}_{4}-$ & $\mathrm{O}$ & 2.5 & 150 & 96 & 90 & $192-194(193-195)^{28}$ \\
\hline $4 e$ & $4-\mathrm{H}_{3} \mathrm{C}-\mathrm{C}_{6} \mathrm{H}_{4}-$ & $\mathrm{O}$ & 1.5 & 120 & 95 & 89 & $214-215(215-216)^{29}$ \\
\hline 4f & $4-\mathrm{MeO}-\mathrm{C}_{6} \mathrm{H}_{4}-$ & $\mathrm{O}$ & 1.5 & 150 & 97 & 86 & $200-202(202-204)^{28}$ \\
\hline $4 \mathrm{~g}$ & 2-Furyl- & $\mathrm{O}$ & 2.0 & 90 & 92 & 81 & $208-210(209-211)^{28}$ \\
\hline $4 \mathrm{~h}$ & $2-\mathrm{Cl}-\mathrm{C}_{6} \mathrm{H}_{4}-$ & $\mathrm{O}$ & 2.5 & 90 & 97 & 84 & $221-222(222-224)^{28}$ \\
\hline $4 \mathbf{i}$ & $4-\mathrm{HO}-\mathrm{C}_{6} \mathrm{H}_{4}-$ & $\mathrm{O}$ & 1.5 & 150 & 96 & 88 & $228-230(230-232)^{28}$ \\
\hline $4 \mathbf{j}$ & $3,4,5-(\mathrm{MeO})_{3}-\mathrm{C}_{6} \mathrm{H}_{2^{-}}$ & $\mathrm{O}$ & 2.0 & 180 & 94 & 83 & $178-180(180-182)^{30}$ \\
\hline $4 \mathbf{k}$ & $4-\mathrm{HO}, 3-\mathrm{MeO}-\mathrm{C}_{6} \mathrm{H}_{3}-$ & $\mathrm{O}$ & 2.0 & 150 & 95 & 87 & $202-203(204-205)^{30}$ \\
\hline 41 & 2-Thienyl & $\mathrm{O}$ & 2.0 & 120 & 93 & 81 & $214-216(215-217)^{28}$ \\
\hline $4 m$ & $2-\mathrm{HO}-\mathrm{C}_{6} \mathrm{H}_{4}-$ & $\mathrm{O}$ & 1.5 & 90 & 91 & 82 & $198-200(200-202)^{30}$ \\
\hline $4 n$ & $2-\mathrm{Br}-\mathrm{C}_{6} \mathrm{H}_{4}-$ & $\mathrm{O}$ & 2.0 & 120 & 92 & 86 & $206-208(205-207)^{33}$ \\
\hline 40 & $3-\mathrm{Br}-\mathrm{C}_{6} \mathrm{H}_{4}-$ & $\mathrm{O}$ & 2.0 & 150 & 94 & 92 & $196-198(196-197)^{33}$ \\
\hline $4 p$ & $2,5-(\mathrm{MeO})_{2}-\mathrm{C}_{6} \mathrm{H}_{3}-$ & $\mathrm{O}$ & 2.5 & 150 & 96 & 94 & $212-214(212)^{35}$ \\
\hline $4 q$ & $3,4-(\mathrm{MeO})_{2}-\mathrm{C}_{6} \mathrm{H}_{3}-$ & $\mathrm{O}$ & 3.0 & 180 & 92 & 89 & $174-176(175-177)^{30}$ \\
\hline $4 r$ & 2-Pyridyl & $\mathrm{O}$ & 1.5 & 150 & 89 & 81 & $212-214(212-214)^{36}$ \\
\hline $4 s$ & 3- $\mathrm{O}_{2} \mathrm{~N}-\mathrm{C}_{6} \mathrm{H}_{4}-$ & $\mathrm{O}$ & 2.0 & 180 & 92 & 82 & $228-230(230-232)^{34}$ \\
\hline $4 t$ & 2- $\mathrm{O}_{2} \mathrm{~N}-\mathrm{C}_{6} \mathrm{H}_{4}-$ & $\mathrm{O}$ & 2.5 & 210 & 94 & 80 & $208-210(210)^{35}$ \\
\hline $4 u$ & $4-\mathrm{Cl}-\mathrm{C}_{6} \mathrm{H}_{4}-$ & $\mathrm{O}$ & 2.0 & 180 & 95 & 88 & $210-212(212-213)^{30}$ \\
\hline $4 v$ & $\mathrm{Ph}-$ & $\mathrm{S}$ & 2.5 & 120 & 92 & 86 & $207-208(208-210)^{28}$ \\
\hline $4 w$ & $4-\mathrm{MeO}-\mathrm{C}_{6} \mathrm{H}_{4}-$ & S & 3.0 & 150 & 95 & 84 & $150-151(150-152)^{28}$ \\
\hline $4 x$ & $3,4,5-(\mathrm{MeO})_{3}-\mathrm{C}_{6} \mathrm{H}_{2-}$ & S & 3.0 & 270 & 91 & 79 & $201-203(202-204)^{32}$ \\
\hline
\end{tabular}

$\mathrm{MW}=$ Microwave irradiation $(280 \mathrm{~W}) ; \Delta=$ Conventional method $\left(80^{\circ} \mathrm{C}\right)$

${ }^{a}$ All the reactions were run till the completion as indicated by TLC

byield after crystallization 


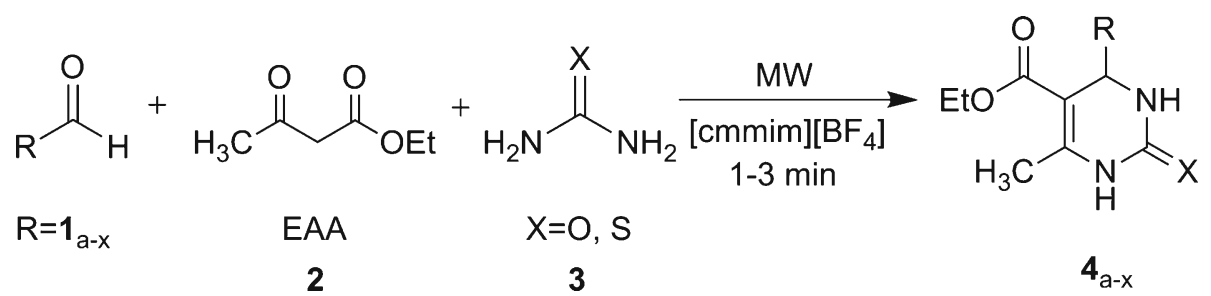

Scheme 2. General reaction scheme for the synthesis of DHPMs.

$\mathrm{C}_{14} \mathrm{H}_{16} \mathrm{~N}_{2} \mathrm{O}_{3}: \mathrm{C}, 64.60 ; \mathrm{H}, 6.20 ; \mathrm{N}, 10.76$. Found: $\mathrm{C}$, 64.61; H, 6.18; N, 10.74. MS: $261(\mathrm{M}+1)$.

2.3b 5-Ethoxycarbonyl-6-methyl-4-(4-fluorophenyl)3,4-dihydropyrimidin-2(1H)-one (4c): IR (KBr) 3240, 2980, 1730, 1640, 1230, 1150, $790 \mathrm{~cm}^{-1} ;{ }^{1} \mathrm{H}$ NMR $\delta 9.25$ (s, 1H), $7.77(\mathrm{~s}, 1 \mathrm{H}), 7.21(\mathrm{~m}, 4 \mathrm{H}), 5.15$ (s, 1H), 3.99 (q, $J=7.1 \mathrm{~Hz}, 2 \mathrm{H}), 2.26(\mathrm{~s}, 3 \mathrm{H}), 1.09$ (t, $J=7.1 \mathrm{~Hz}, 3 \mathrm{H}) ;{ }^{13} \mathrm{C}$ NMR $\delta 13.9,17.8,53.6,59.5$, 123.4, 127.5, 145.2, 149.3, 151.6, 152.1, 164.8. Calc. for $\mathrm{C}_{14} \mathrm{H}_{15} \mathrm{FN}_{2} \mathrm{O}_{3}: \mathrm{C}, 60.42 ; \mathrm{H}, 5.43 ; \mathrm{N}, 10.07$. Found: C, 60.44; H, 5.42; N, 10.10 .

2.3c 5-Ethoxycarbonyl-6-methyl-4-(4-methoxyphenyl)3,4-dihydropyrimidin-2(1H)-one (4f): $\mathrm{IR}(\mathrm{KBr}) 3206$, 2956, 1740, 1679, 1245, 1180, 1040, $875 \mathrm{~cm}^{-1} ;{ }^{1} \mathrm{H}$ NMR $\delta 9.14(\mathrm{~s}, 1 \mathrm{H}), 7.66(\mathrm{~s}, 1 \mathrm{H}), 6.99(\mathrm{~m}, 4 \mathrm{H}), 5.07$ $(\mathrm{s}, 1 \mathrm{H}), 3.96(\mathrm{q}, J=6.8 \mathrm{~Hz}, 2 \mathrm{H}), 3.70(\mathrm{~s}, 3 \mathrm{H}), 2.23(\mathrm{~s}$, $3 \mathrm{H}), 1.09(\mathrm{t}, J=6.8 \mathrm{~Hz}, 3 \mathrm{H}) ;{ }^{13} \mathrm{C} \mathrm{NMR} \delta 14.5,18.2$, 53.78, 55.47, 59.60, 99.9, 114.1, 127.8, 136.4, 148.3, 158.8, 165.8. Calc. for $\mathrm{C}_{15} \mathrm{H}_{18} \mathrm{~N}_{2} \mathrm{O}_{4}$ : C, 62.06; $\mathrm{H}, 6.25$; N, 9.65. Found: C, 62.04; H, 6.28; N, 9.67. MS: 291 $(\mathrm{M}+1)$.

2.3d 5-Ethoxycarbonyl-6-methyl-4-(3,4,5-trimethoxyphenyl)-3,4-dihydropyrimidin-2(1H)-thione $(4 x)$ : IR (KBr) 3284, 2967, 1720, 1632, 1234, 1140, $780 \mathrm{~cm}^{-1} ;{ }^{1} \mathrm{H}$ NMR $\delta 10.21(\mathrm{~s}, 1 \mathrm{H}), 9.49(\mathrm{~s}, 1 \mathrm{H}), 7.29$ $(\mathrm{m}, 2 \mathrm{H}), 5.02(\mathrm{~s}, 1 \mathrm{H}), 6.40(\mathrm{~s}, 2 \mathrm{H}), 3.94(\mathrm{q}, J=6.6 \mathrm{~Hz}$, $2 \mathrm{H}), 3.57(\mathrm{~s}, 9 \mathrm{H}) 2.13(\mathrm{~s}, 3 \mathrm{H}), 1.04(\mathrm{t}, J=7.0 \mathrm{~Hz}$, $3 \mathrm{H}) ;{ }^{13} \mathrm{C}$ NMR $\delta 14.9,17.7,54.2,56.1,60.1,60.4$, 101.2, 103.5, 137.1, 139.4, 145.7, 153.3, 165.4, 174.5. Calc. for $\mathrm{C}_{17} \mathrm{H}_{22} \mathrm{~N}_{2} \mathrm{O}_{5} \mathrm{~S}$ : C, 55.72; H, 6.05; N, 7.64. Found: C, 55.69; H, 6.03; N, 7.62.

\section{Results and discussion}

A variety of aldehydes $(\mathbf{1}-\mathrm{a}-\mathrm{x})$ were chosen to be condensed with ethyl acetoacetate (2) and urea/thiourea (3) as shown in the scheme 2.
In order to carry out such transformation by eliminating the use of molecular solvent, we examined the influence of MW irradiation on a neat mixture of ethyl acetoacetate, benzaldehyde, urea and carboxy functionalized ionic liquid 1-carboxymethyl3-methylimidazolium tetrafluoroborate $[\mathrm{cmmim}]\left[\mathrm{BF}_{4}\right]$. In order to investigate the proportion of IL, irradiation time and power level of MW set-up, we carried out series of experiments. From these experiments, we found an optimum set of conditions that afford DHPMs in excellent isolated yields. Evidently, this optimum condition employed aldehyde $\mathbf{1}$, ethyl acetoacetate $\mathbf{2}$ and urea (or thiourea) 3 in the ratio of 1.0:1.0:1.1 by using $200 \mathrm{mg}$ [ $\mathrm{cmmim}]\left[\mathrm{BF}_{4}\right]$ as reaction promoter at power level $4(280 \mathrm{~W})$. Time taken for the completion of each conversion, aldehyde employed, isolated yields and melting points of products are summarized in table 1 . The amount of IL does not appear to be critical as we have run successful experiments with 50$200 \mathrm{mg}$ of IL per mmol of aldehyde. However, the presence of about $200 \mathrm{mg}$ of IL ensures the homogeneity of the reaction mixture in particular when solid aldehydes were employed. All the reactions were monitored by TLC and taken to completion. All the compounds were well-characterized by melting points, ${ }^{1} \mathrm{H}$ NMR, ${ }^{13} \mathrm{C}$ NMR and DEPT-135 spectral data. Additional confor-

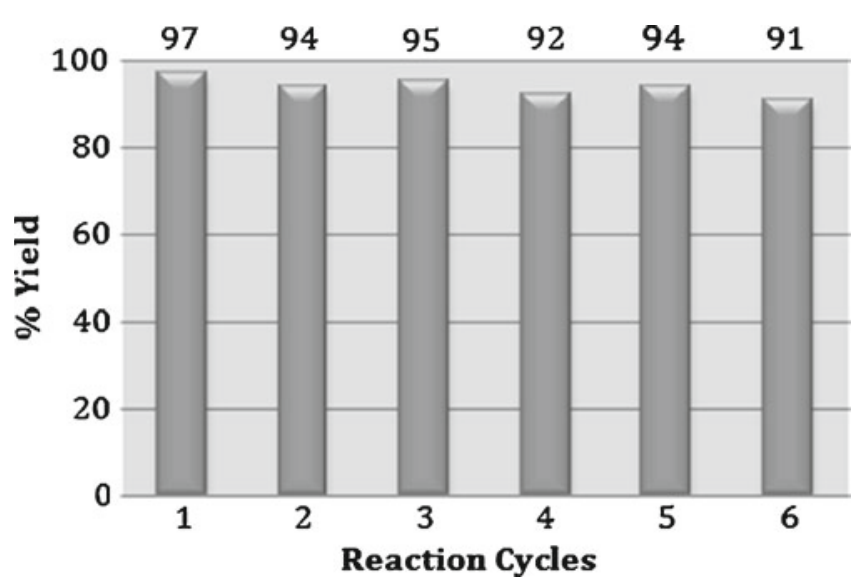

Figure 1. Recyclability of ionic liquid. 


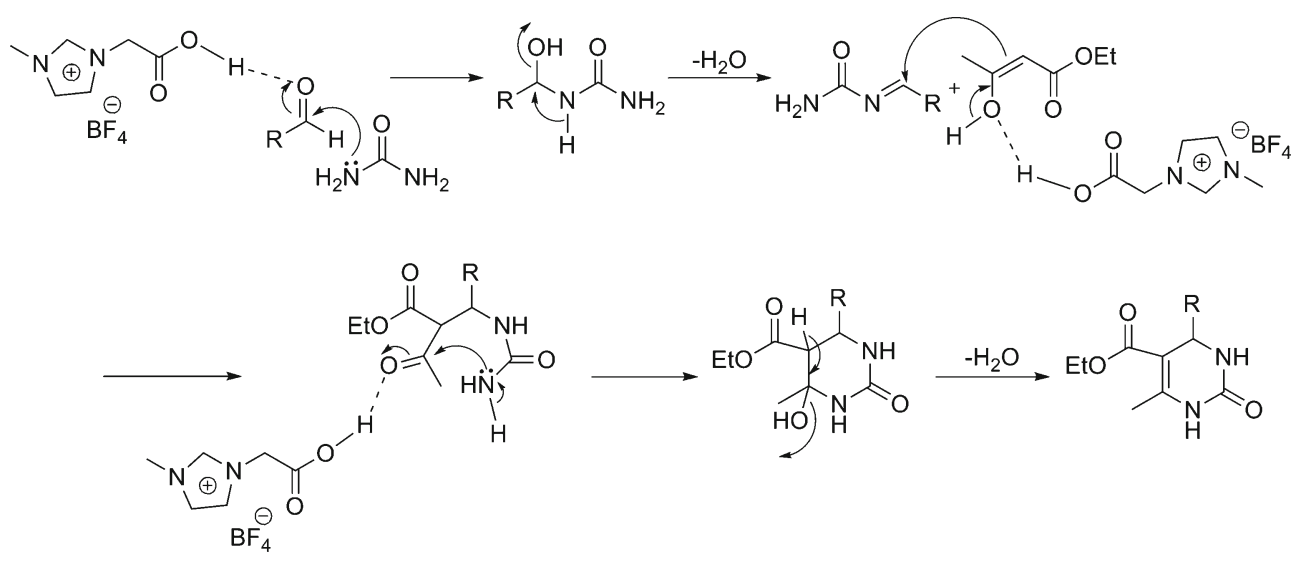

Scheme 3. Plausible mechanistic pathway.

mation of compounds was also achieved by IR and mass spectral studies. All the data were in agreement with the reported literature. All the aldehydes have reacted in short reaction times under MW irradiations to afford DHPMs in excellent isolated yields. MW/ILs induced protocol showed the ability to tolerate variations in aromatic aldehydes containing both electron donating and electron withdrawing substituents.

In a typical experiment, three reaction components along with IL were simply mixed in a $25 \mathrm{~mL}$ round bottom flask and irradiated under MW. After cooling, the products were easily isolated by dilution with water followed by filtration of precipitated DHPMs. The DHPMs, thus isolated were pure enough for all practical purposes. However, all the DHPMs were subjected to crystallization and the yields reported after purification step. The aqueous filtrate was subjected to vacuum at $80^{\circ} \mathrm{C} / 10 \mathrm{~mm} \mathrm{Hg}$ for $4 \mathrm{~h}$ to remove water and leave behind $[\mathrm{cmmim}]\left[\mathrm{BF}_{4}\right]$ pure enough for the next run. The ionic liquid thus recycled was used at least six times for the microwave-induced reaction of $\mathbf{4 a}$ with prominent retention in its activity. The obtained results are plotted in figure 1.

From the series of experiments, it was observed that the reaction did not proceed even after several minutes of irradiation in molecular solvents such as ethanol, ethyl acetate and acetonitrile instead of IL under similar MW set-up conditions. No formation of the desired heterocycle was observed when reaction was carried out under simple stirring at $30^{\circ} \mathrm{C}$. For the comparison purpose, the reactions were also carried out in the presence of the same amount of the $[\mathrm{cmmim}]\left[\mathrm{BF}_{4}\right]$ in an oil bath at $80^{\circ} \mathrm{C}$. The results are summarized in table 1 . It is clear that the reactions under microwave irradiation led to relatively high yields in shorter reaction time. From this experimental evidence, it can be stated that it is the synergetic effect of MW/ILs couple that has promoted this transformation in absence of any added catalyst.
IL promotes the reactions due to its inherent Brønsted acidity. Hydrogen bonding is formed between carboxylic proton of IL and carbonyl oxygen of aldehyde as well as ethyl acetoacetate during the reaction. The formation of hydrogen bond between IL and substrate leads them to the activation. ${ }^{27}$ Based on this, the plausible mechanistic pathway for this reaction is suggested (scheme 3).

\section{Conclusion}

The combined effect of microwave-ionic liquid couple provides an easy and green route to synthesize DHPMs via Biginelli reaction. The milder reaction conditions, absence of additional catalyst, high reaction rates, excellent yields, easy work up procedures and MW-IL strategy make this procedure an attractive alternative to the conventional acid/base catalysed thermal processes and is environment friendly with minimal or no waste.

\section{Acknowledgements}

Authors thank Head, Department of Chemistry, Sardar Patel University for providing necessary research facilities. DKR is grateful to authorities of Sardar Patel University, Vallabh Vidyanagar for allocation of research funding in the form of seed grant-2011. He also thanks the University Grants Commission (UGC), New Delhi for providing Meritorious Fellowship.

\section{References}

1. Kappe C O 1993 Tetrahedron 496937

2. (a) Cho H, Ueda M, Shima K, Mizuno A, Hayashimatsu M, Ohnaka Y, Takeuchi Y, Hamaguchi M and Aisaka K 1989 J. Med. Chem. 32 2399; (b) Atwal K S, Rovnyak G C, Kimball S D, Floyd D M, Moreland S, Swanson 
B N, Gougoutas J Z, Schwartz J, Smillie K M and Malley M F 1990 J. Med. Chem. 33 2629; (c) Rovnyak G C, Kimball S D, Beyer B, Cucinotta G, DiMarco J D, Gougoutas J, Hedberg A, Malley M and McCarthy J P 1995 J. Med. Chem. 38119

3. (a) Atwal K S, Swanson B N, Unger S E, Floyd D M, Moreland S, Hedberg A and O'Reilly B C $1991 \mathrm{~J}$. Med. Chem. 34 806; (b) Rovnyak G C, Atwal K S, Hedberg A, Kimball S D, Moreland S, Gougoutas J Z, O'Reilly B C, Schwartz J and Malley M F 1992 J. Med. Chem. 35 3254; (c) Grover G J, Dzwonczyk S, McMullen D M, Normandin D E, Parham C S, Sleph P G and Moreland S 1995 J. Cardiovasc. Pharmacol. 26289

4. (a) Wong W C, Lagu B, Nagarathnam D, Marzabadi M $\mathrm{R}$ and Gluchowski C PCT Int. Appl. WO 97 42,956 and WO 98 51,311; (b) Nagarathnam D, Wong W C, Miao S W, Patane M A and Gluchowski C PCT Int. Appl. WO 97 17,969; (c) Sidler D R, Larsen R D, Chartrain M, Ikemoto N, Roberge C M, Taylor C S, Li W and Bills G F PCT Int. WO 9907695

5. Bruce M A, Pointdexter G S, Johnson G PCT Int. Appl. WO 98 33,791

6. Snider B B and Shi Z 1993 J. Org. Chem. 583828

7. Biginelli P 1893 Gazz. Chim. Ital. 23360

8. (a) Bigi F, Carloni S, Frullanti B, Maggi R and Sartori G 1999 Tetrahedron Lett. 40 3465; (b) Kappe C O and Falsone S F 1998 Synlett. 718; (c) Hu E H, Sidler D R and Dolling U-H 1998 J. Org. Chem. 63 3454

9. (a) Oreilly B C and Atwal K S 1987 Heterocycles 26 1185; (b) Atwal K S, Oreilly B C, Gougoutas J Z and Malley M F 1987 Heterocycles 26 1189; (c) Shutalev A D and Kuksa V A 1997 Khim geterotsikl+ 105; (d) Shutalev A D, Kishko E A, Sivova N V and Kuznetsov A Y 1998 Molecules 3 100; (e) Rani V R, Srinivas N, Kishan M R, Kulkarni S J and Raghavan K V 2001 Green Chem. 3 305; (f) Lu J, Bai Y, Wang Z, Yang B and Ma H 2000 Tetrahedron Lett. 41 9075; (g) Ma Y, Qian C, Wang L and Yang M $2000 \mathrm{~J}$. Org. Chem. 65 3864; (h) Ranu B C, Hajra A and Jana U 2000 J. Org. Chem. 656270

10. Yadav J S, Reddy B V S, Reddy E J and Ramalingam T 2000 J. Chem. Res., Synop. 354

11. Mukhopadhyay C, Datta A and Banik B K 2007 J. Heterocycl. Chem. 44979

12. Mishra B G, Kumar D and Rao V S 2006 Catal. Commun. 7457
13. Pisani L, Prokopcová H, Kremsner J M and Kappe C O 2007 J. Comb. Chem. 9415

14. Polshettiwar V and Varma R S 2007 Tetrahedron Lett. 487343

15. Saxena I, Borah D C and Sarma J C 2005 Tetrahedron Lett. 461159

16. Kumar D, Sundaree M S and Mishra B G 2006 Chem. Lett. 351074

17. Kapoor K K, Ganai B A, Kumar S and Andotra C S 2006 Can. J. Chem. 84433

18. Tu S J, Fang F, Miao C B, Jiang H and Shi D Q 2003 Chin. J. Chem. 21706

19. Hazarkhani H and Karimi B 2004 Synthesis 1239

20. Shanmugam P, Annie G and Perumal P T 2003 J. Heterocycl. Chem. 40879

21. Liang B, Wang X, Wang J-X and Du Z 2007 Tetrahedron 631981

22. Kappe C O 2002 Curr. Opin. Chem. Biol. 6 314; (b) Oliver Kappe C 2008 Chem. Soc. Rev. 371127

23. Yi F, Peng Y and Song G 2005 Tetrahedron Lett. 46 3931; (b) Zare A, Hasaninejad A, Khalafi-Nezhad A, Moosavi Zare A R and Parhami A 2007 Arkivoc 2007 105

24. Welton T 1999 Chem. Rev. 992071

25. Kappe C O 2008 Chem. Soc. Rev. 371127

26. Li J, Peng Y and Song G 2005 Catal. Lett. 1023

27. Dadhania A N, Patel V K and Raval D K 2011 J. Braz. Chem. Soc. 22511

28. Fu N-Y, Yuan Y-F, Cao Z, Wang S-W, Wang J-T and Peppe C 2002 Tetrahedron 584801

29. Chari M A, Shobha D, Kumar T K and Dubey P K 2005 arkivoc $\mathbf{x v} 74$

30. Paraskar A S, Dewkar G K and Sudalai A 2003 Tetrahedron Lett. 443305

31. Reddy C V, Mahesh M, Raju P V K, Babu T R and Reddy V V N 2002 Tetrahedron Lett. 432657

32. Gholap A R, Venkatesan K, Daniel T, Lahoti R J and Srinivasan K V 2004 Green Chem. 6147

33. Pasunooti K K, Chai H, Jensen C N, Gorityala B K, Wang S and Liu X-W 2011 Tetrahedron Lett. 5280

34. Garima, Srivastava V P and Yadav L D S 2010 Tetrahedron Lett. 516436

35. Rosi Reddy K, Venkateshwar Reddy C, Mahesh M, Raju P V K and Narayana Reddy V V 2003 Tetrahedron Lett. 448173

36. Shanmugam P, Annie G and Perumal P T 2003 J. Heterocycl. Chem. 40879 